\title{
Perception and Uses of Stakeholders' Power on Health and Safety Risk Management in Construction Projects in
}

\section{Tanzania}

\author{
Sarah Phoya and Harriet Eliufoo \\ School of Construction Economics and Management, Ardhi University, Dar es salaam P.O. Box 35276, Tanzania
}

\begin{abstract}
Key project stakeholders such as clients, consultant teams, contractors and workers have different sources of power to implement projects. How these powers influence health and safety risk management is not well documented. This article therefore assesses the perception and uses of stakeholders' power on health and safety in risk management in construction projects in Tanzania, specifically focuses on sources and types of power, how stakeholders perceive their power, how they use power on health and safety risk management, and what factors hinders their use of power. A case study strategy was adopted and four large on-going construction projects in Dar es Salaam Tanzania were involved. Data was collected through in-depth interviews with clients, consultants, contractors and construction workers. Findings indicate that stakeholders have different sources of power such as technical expertise, legitimate, political position, resources information to influence health and safety risk management. Nonetheless, the use of these powers was generally limited due to low level of knowledge on health and safety risk management among stakeholders, wrong perception on their roles, insufficient health and safety regulations and weak procurement system. The research recommends that, in order to realize health and safety performance through using stakeholder's power, there is a need of clear definition of stakeholders' role and responsibilities on health and safety, wide knowledge and experiences on health and safety risk management, strong regulatory system and procurement system.
\end{abstract}

Key words: Stakeholders' power, perception and uses, health and safety risks management.

\section{Introduction}

The nature of construction activities are associated with high health and safety risk factors. This being the case, there is high spate of accidents in construction projects. Nevertheless, many sources of risk factors range from the inception stage of the project to completion stage and decisions to manage them require collective effort and power from all stakeholders involved in projects such as clients, consultant teams, contractors and workers.

Power, as stated by Jasperson et al. [1] is an ability to influence decisions of a particular event. Other scholars have defined power as an ability to influence the intentions and actions of other stakeholders [2] or the capacity to act effectively [3]. What emerges in

Corresponding author: Sarah Phoya, lecturer, research fields: health and safety risk management. these definitions reveal that power has to do with possession of control, authority or influence over others. One can say that, power is a potential energy that either being a driver of activity or active resource as a decision maker. This has been supported by Arnstein [4] that power is the central tool for stakeholder to participate in any activity.

Essentially, project stakeholders have different levels of power with which can influence certain decisions and sometimes control actions of an activity in a project. Stakeholders as defined by Freeman [5] are individuals or organizations that are actively involved in a project or whose interest may be affected as the result of project execution or project completion. They can be classified as either internal stakeholders who are directly involved in implementation of the project such as project clients, project management consultants (architects, engineers 
and quantity surveyors) and project contractors, sub-contractors, workers, or external stakeholders who are not directly involved in the implementation of the project but are affected by the project such as community members. This research has focused only on internal stakeholders.

These stakeholders in one way or another are involved on health and safety risk management such as identification of risk factors (hazards), analysis, evaluation of risks, risk control, communication, consultation, monitoring and review of the level of risk in construction projects [6]. Nonetheless, there has been limited knowledge regarding the influence of stakeholders' power on health and safety risk management, specifically, sources and types of power, stakeholders' perception of their power, how they use power on health and safety risk management and what factors hinder use of their power. Therefore, this paper contributes to the understanding of how stakeholders perceive the power they hold and how they use their power to improve health and safety risk management in construction project stages such as briefing, design, procurement and construction.

\section{Literature Review}

\subsection{Theoretical Background on Stakeholders'Power}

One of the most influential theories of power has been done by French and Raven [7]. They attempted to determine five sources of power which include: legitimate, reward, coercive, expert and referent. However, they grouped these sources of power into two categories: positional power (legitimate, reward and coercive) and personal power (expert, and referent). Position power derived from statutory or organizational authorities where there is formal authority to reward, punish and control information. Personal power derived from an individual's personal attributes or human relationship influences. These sources of power despite being studies by many researchers [8-10] French and Raven's theory of power sources remain intact.
Legitimate power comes from the belief that a person has the formal right to make demands, and to expect compliance and obedience from others [7], which is derived from social hierarchies, cultural norms, and organizational structure. This type of power, however, can be unpredictable and unstable: if one looses a title or position, legitimate power can instantly disappear [10].

Reward power on the other hand, results from one person's ability to compensate another for compliance. The examples of reward include pay raises or bonuses, promotions, favorable work assignments, new equipment, recognition and training opportunities. For example, contractors or workers who adhere to safety procedures can be rewarded with certificates of recognition or bonus. Reward power influences others' behavior and can lead to better performance [11]. Nonetheless, when the rewards do not have enough perceived value to others, the power can be weakened. This is also the same for coercive power where peoples' belief is that a person can punish others for non-compliance.

Expert power is a person's ability to influence others' behavior because of recognized knowledge, skills, or abilities $[11,12]$. For example, professionals like architects, engineers and quantity surveyors are technical experts therefore have expert power. The issue of credibility, trustworthy and relevance is likewise associated with expert power [13]. For example, a client may take advice of health and safety from an architect or engineer because there is a proof that they have appropriate credentials.

Referent is person's ability to influence others' behavior because of their attractiveness, worthiness, and right to command respect from others. Referent power develops out of admiration of another and a desire to be like that person. For example, a good project manager may influence others' behavior to adhere to health and safety issues because he is admired and has a good reputation, attractive personal characteristics, or a certain level of charisma [12]. 
Other sources of power include resourcing and political. Resourcing is inevitably linked with power, since power can be seen as concerning, ownership and control over resources [14]. Resource rights are exemplified by the ability to assign people offices, space and financial success. Political power on the other hand is derived from the exercise of strategic processes. Politics is typified by the use of creeping commitment as a strategy for drawing cautious practitioners into taking revolutionary actions. A good example is when workers join a trade union or elect their representatives in workplaces. Possession of information has been found to constitute an additional source/element of power [10] and a socio-political connection (who is known) has been suggested by Hersey et al. [15] to constitute another source. What emerges from this discussion is that there are different sources of power among stakeholders. These include position, personal, political, resources, information, status and connections. Needless to say, these sources of power have a potential to provide opportunity for one to act in one way or another to improve health and safety risk management in construction sites.

\subsection{Stakeholders' Power and Risk Management} Process

A great deal of power in which stakeholders hold on health and safety is embedded in the roles and responsibilities they perform from the inception to the construction stage [6]. Therefore, through different activities performed by key stakeholders such as clients, consultant teams, contractors and workers, risk factors can be identified, analyzed, controlled and communicated [16]. For example, different authors have discussed the role of clients in managing health and safety risks [17-19]. They maintained that, clients have a major role in project implementation, and therefore, they have a power push for the safety requirements from idea to completion of projects. This has been reflected in different regulations in different countries which require clients to ensure health and safety is managed throughout the projects [20-22]. The core issues which require clients to have responsibilities on health and safety include his/her position (position power) in selecting consultant team and contractors. Huang and Hinze [23] ascertain that a client is the financier who has resource control power. This is demonstrated in the way clients encourage designers to address safety issues in the designs, and how they inspire contractors to implement safety management during construction.

PMs (Project Managers) or project leaders on the other hand, are viewed as the single point of responsibility for all key decisions of the project where they play a vital role in the execution of project excellence [24]. Indeed, the PM is involved in planning, organizing, staffing, motivating, directing, leading, tracking, measuring, and controlling of all aspects of a project [25] which need commitment and necessary skills. On the other hand, conditions of contracts have vested much of the power to PMs, specifically, issue of instruction, approval payments, and issuing of certificates. As a formal leader of the team, the project leader is legitimately conferred with the formal power concomitant with his/her occupation of the managerial position. Therefore, they have legitimate power. Project leaders also possess expert power because they need to have necessary skills in management especially identifying, assessing, communication in controlling and managing health and safety risk factors in construction projects.

The architects, engineers and quantity surveyors do consider health and safety aspects when they are involved in their task in the projects. Architects and engineers identify, appraise and control all the risk from a design perspective [26]. Quantity surveyors warrant health and safety aspects in the BOQ (Bills of Quantities) by drawing up specifications and ensure principal contractors incorporate adequate allowances for health and safety [27]. Being able to influence health and safety aspect in designs and BOQ is an indication of high expert power. 
Contractors, especially site managers have traditionally and legally borne the largest portion of health and safety risk responsibility in construction [28]. The situation is the same in Tanzania as the responsibility of health and safety regulations is being borne by contractors [28, 29].

The demands for construction workers in Tanzania hence constitute the obligation to comply with the safety and health law, instructions and procedures in health and safety policy. It extends to use of safety devices and protective equipment, to report to immediate supervisors of any incident which they believe is likely to cause a hazard and which they cannot rectify. It also constitutes power to select safety protective equipment, join trade unions [30] and elect their representative for health and safety risk management [29].

\section{Methodology}

Four on-going construction projects in Dar es Salaam were selected in the case study through judgmental sampling. The projects were selected because they showed features of multi-stakeholders participation in health and safety risk management. Face-to-face interviews were conducted with key stakeholders. This included clients, project managers, architects, engineers, quantity surveyors, site managers and workers. A total of four clients, two project managers, four architects, four engineers, four quantity surveyors, four site managers/foreman and 20 workers were interviewed.

The interview began by asking stakeholders to indicate the type of power they hold in the project and to rate their level of power in various activities in the construction project where responses ranged from low, medium to high. Also, they were asked to rate how they used their power to influence health and safety risk management. The possession and the use of powers of these stakeholders were assessed at four stages of a project: briefing, designing, procurement and construction phases. The briefing phase in this context refers to the early stages of a scheme; from the time a client conceives an idea to the point where a client communicates ideas to the consultant. Design stage, on the other hand is when the designer starts conceptual drawings through its development and up to production of working drawings and BOQ. Procurement is a stage when a contractor is selected. The construction stage is the time the contractor(s) carry out work on site.

\section{Finding and Discussion}

Qualitative content analysis was applied to discern the perception and the use of power among stakeholders in different activities. The respondents were asked to rate these attributes as high, moderate or low in scores of 1,2 and 3 , where 1 is low and 3 is high.

The results are presented in Tables 1-4, respectively. As illustrated in Table 1, client's perception of power to influence health and safety aspects during the briefing stage is high. Further discussion had clients ascertain having resources power, ownership power and position power. Regarding to how they use their power to influence health and safety risk management during the briefing stage, it was revealed that it was moderately used. From one of the case study, a client who was not a financier revealed he had to adhere to the financier's requirements and this led to less resource control power. Furthermore, two clients also revealed to have had less power in the selecting of consultants based on safety merit because consultants' employment was dominantly guided by procurement regulations. These projects were public projects and they were by law required to adhere to procurement regulations. The procurement regulations provide a procedure for employing consultants based on general competence without any emphasis on health and safety merit in the evaluation criteria.

Table 1 further shows that, apart from the client, project managers acknowledge having high power in communication of project information since are in a 
Construction Projects in Tanzania

Table 1 Perceived power and use of power by stakeholders at briefing stage.

\begin{tabular}{|c|c|c|c|c|c|c|c|}
\hline \multirow{2}{*}{ Activity performed } & \multirow{2}{*}{ Stakeholders } & \multicolumn{3}{|c|}{ Perception of power } & \multicolumn{3}{|c|}{ The uses/influence of power } \\
\hline & & 1 & 2 & 3 & 1 & 2 & 3 \\
\hline \multirow{3}{*}{$\begin{array}{l}\text { Setting project requirements which } \\
\text { emphasizes health and safety aspects on } \\
\text { risk identification and control }\end{array}$} & Clients & & & $\checkmark \checkmark \checkmark \checkmark$ & & $\checkmark \checkmark \checkmark$ & $\checkmark$ \\
\hline & Project managers & & $\checkmark$ & & & $\checkmark \checkmark$ & \\
\hline & Architects & & $\checkmark$ & & $\checkmark \checkmark$ & $\checkmark \checkmark$ & \\
\hline \multirow{5}{*}{$\begin{array}{l}\text { Employment of consultant based on safety } \\
\text { merits and capability to identify and } \\
\text { manage risks }\end{array}$} & Clients & & $\checkmark$ & $\checkmark \checkmark \checkmark$ & & $\checkmark \checkmark$ & $\checkmark \checkmark$ \\
\hline & Project managers & & & $\checkmark$ & $\checkmark \checkmark \checkmark \checkmark$ & & \\
\hline & Architects & & $\checkmark$ & & $\checkmark \checkmark \checkmark \checkmark$ & & \\
\hline & Quantity surveyor & & & & $\checkmark \checkmark \checkmark \checkmark$ & & \\
\hline & Engineers & & & & $\checkmark \checkmark \checkmark \checkmark$ & & \\
\hline \multirow{5}{*}{$\begin{array}{l}\text { Communicating project information with } \\
\text { emphasis on health and safety risk aspects }\end{array}$} & Clients & & & $\checkmark \checkmark \checkmark \checkmark$ & $\checkmark$ & $\checkmark \checkmark$ & $\checkmark$ \\
\hline & Project managers & & & $\checkmark \checkmark$ & & $\checkmark \checkmark \checkmark$ & $\checkmark$ \\
\hline & Architects & & $\checkmark \checkmark$ & $\checkmark \checkmark$ & $\checkmark \checkmark$ & $\checkmark \checkmark$ & \\
\hline & Quantity Surveyors & & $\checkmark \checkmark \checkmark \checkmark$ & & $\checkmark \checkmark \checkmark \checkmark$ & & \\
\hline & Engineers & $\checkmark$ & $\checkmark \checkmark \checkmark \checkmark$ & & $\checkmark \checkmark \checkmark \checkmark$ & & \\
\hline
\end{tabular}

Table 2 Perceived power and the use of power by stakeholders at design stage.

\begin{tabular}{|c|c|c|c|c|c|c|c|}
\hline \multirow{2}{*}{ Activity performed } & \multirow{2}{*}{ Stakeholders } & \multicolumn{3}{|c|}{ Perceived power } & \multicolumn{3}{|c|}{ The use/influence of power } \\
\hline & & 1 & 2 & 3 & 1 & 2 & 3 \\
\hline \multirow{5}{*}{$\begin{array}{l}\text { Design Concepts that incorporate health } \\
\text { and safety }\end{array}$} & Clients & & $\checkmark \checkmark \checkmark$ & $\checkmark$ & $\checkmark \checkmark \checkmark$ & & \\
\hline & Project managers & & & & $\checkmark \checkmark$ & & \\
\hline & Architects & & $\checkmark$ & $\checkmark \checkmark \checkmark$ & $\checkmark \checkmark \checkmark$ & $\checkmark$ & \\
\hline & Quantity surveyor & & $\checkmark \checkmark \checkmark \checkmark$ & & $\checkmark \checkmark \checkmark$ & $\checkmark$ & \\
\hline & Engineers & & $\checkmark \checkmark \checkmark \checkmark$ & & $\checkmark \checkmark \checkmark \checkmark$ & & \\
\hline \multirow{5}{*}{$\begin{array}{l}\text { Detail Design that incorporate health and } \\
\text { safety }\end{array}$} & Client & $\checkmark$ & $\checkmark \checkmark \checkmark$ & & $\checkmark \checkmark \checkmark$ & & \\
\hline & Project manager & & & $\checkmark \checkmark$ & $\checkmark \checkmark$ & & \\
\hline & Architect & & & $\checkmark \checkmark \checkmark \checkmark$ & $\checkmark \checkmark \checkmark$ & $\checkmark$ & \\
\hline & Quantity surveyor & & $\checkmark \checkmark \checkmark$ & $\checkmark$ & $\checkmark \checkmark \checkmark \checkmark$ & & \\
\hline & Engineers & & $\checkmark \checkmark$ & $\checkmark \checkmark$ & $\checkmark \checkmark \checkmark$ & $\checkmark$ & \\
\hline \multirow{5}{*}{$\begin{array}{l}\text { BOQ and cost estimates that incorporate } \\
\text { health and safety }\end{array}$} & Client & $\checkmark$ & $\checkmark \checkmark \checkmark$ & & & $\checkmark \checkmark \checkmark \checkmark$ & \\
\hline & Project manager & & & $\checkmark \checkmark$ & & $\checkmark$ & $\checkmark$ \\
\hline & Architect & & $\checkmark \checkmark \checkmark \checkmark$ & & $\checkmark \checkmark \checkmark \checkmark$ & & \\
\hline & Quantity surveyor & & & $\checkmark \checkmark \checkmark \checkmark$ & & $\checkmark \checkmark \checkmark \checkmark$ & \\
\hline & Engineers & & $\checkmark \checkmark \checkmark \checkmark$ & & $\checkmark \checkmark \checkmark \checkmark$ & & \\
\hline
\end{tabular}

position to discuss and advice on various aspects of project's requirements. Either way, the project managers have to ensure that clients understand the decisions to be made and that there is a balanced opinion in making those decisions.

During design stage as indicated in Table 2, the architects, the engineers and the quantity surveyors perceive themselves to have high power specifically when they are performing their specific tasks. This underscores the fact that there is high expertise power in performing tasks in construction projects. The project managers are noted to have maintained considerable power throughout the design stage. The fact that project managers interpret plans, specifications, the BOQs and cost estimates to ensure they meet client's requirements is interpreted by the researcher as a source of his high power throughout the design stage. A further observation is that although designers acknowledged having high power during the design stage, they did not use it. This was revealed in three out of the four projects. The reason pointed out by the designers is that it is costly and 
Table 3 Perceived power and the use of power by stakeholders at procurement stage.

\begin{tabular}{|c|c|c|c|c|c|c|c|}
\hline \multirow{2}{*}{ Task/activity performed } & \multirow{2}{*}{ Stakeholders } & \multicolumn{3}{|c|}{ Perceived power } & \multicolumn{3}{|c|}{ The use/influence of power } \\
\hline & & 1 & 2 & 3 & 1 & 2 & 3 \\
\hline \multirow{5}{*}{$\begin{array}{l}\text { Preparation of tender documents that } \\
\text { emphasize the aspect of health and safety }\end{array}$} & Client & & $\checkmark \checkmark \checkmark$ & $\checkmark$ & & $\checkmark \checkmark \checkmark \checkmark$ & \\
\hline & Project manager & & & $\checkmark \checkmark$ & & $\checkmark$ & $\checkmark$ \\
\hline & Architect & & $\checkmark \checkmark \checkmark$ & $\checkmark$ & & $\checkmark \checkmark \checkmark \checkmark$ & \\
\hline & Quantity surveyor & & & $\checkmark \checkmark \checkmark \checkmark$ & & $\checkmark \checkmark \checkmark$ & $\checkmark$ \\
\hline & Engineers & & $\checkmark \checkmark \checkmark \checkmark$ & & $\checkmark \checkmark \checkmark$ & $\checkmark$ & \\
\hline \multirow{5}{*}{$\begin{array}{l}\text { Tender evaluation that considers } \\
\text { contractor's capability and commitment } \\
\text { on health and safety aspects }\end{array}$} & Client & $\checkmark$ & $\checkmark \checkmark \checkmark$ & & $\checkmark \checkmark$ & $\checkmark \checkmark$ & \\
\hline & Project manager & & & $\checkmark \checkmark$ & & $\checkmark \checkmark$ & $\checkmark \checkmark$ \\
\hline & Architect & & $\checkmark \checkmark$ & $\checkmark \checkmark$ & $\checkmark \checkmark$ & $\checkmark \checkmark$ & \\
\hline & Quantity surveyor & & $\checkmark \checkmark$ & $\checkmark \checkmark$ & & $\checkmark \checkmark \checkmark$ & $\checkmark$ \\
\hline & Engineers & & $\checkmark \checkmark \checkmark \checkmark$ & & $\checkmark \checkmark \checkmark$ & $\checkmark$ & \\
\hline \multirow{5}{*}{$\begin{array}{l}\text { Awarding contract to a contractor who is } \\
\text { committed to health and safety }\end{array}$} & Client & & & $\checkmark \checkmark \checkmark \checkmark$ & $\checkmark \checkmark$ & $\checkmark \checkmark$ & \\
\hline & Project manager & & $\checkmark \checkmark$ & & $\checkmark \checkmark$ & $\checkmark$ & $\checkmark$ \\
\hline & Architect & $\checkmark \checkmark$ & $\checkmark \checkmark$ & & $\checkmark \checkmark \checkmark \checkmark$ & & \\
\hline & Quantity surveyor & & $\checkmark \checkmark \checkmark \checkmark$ & & $\checkmark \checkmark \checkmark \checkmark$ & & \\
\hline & Engineers & $\checkmark \checkmark$ & $\checkmark \checkmark$ & & $\checkmark \checkmark \checkmark \checkmark$ & & \\
\hline
\end{tabular}

Table 4 Perceived power and the use of power by stakeholders at design stage.

\begin{tabular}{|c|c|c|c|c|c|c|c|}
\hline \multirow{2}{*}{ Task/activity performed } & \multirow{2}{*}{ Stakeholders } & \multicolumn{3}{|c|}{ Perceived power } & \multicolumn{3}{|c|}{ The uses of power } \\
\hline & & 1 & 2 & 3 & 1 & 2 & 3 \\
\hline \multirow{7}{*}{$\begin{array}{l}\text { Risk identification } \\
\text { Safety induction training, } \\
\text { risk control provision of } \\
\text { PPE (personal protective } \\
\text { equipment), welfare } \\
\text { facilities }\end{array}$} & Clients & & $\checkmark \checkmark \checkmark$ & $\checkmark$ & & $\checkmark \checkmark \checkmark$ & $\checkmark$ \\
\hline & Project managers & & $\checkmark \checkmark \checkmark$ & $\checkmark$ & & $\checkmark \checkmark \checkmark$ & $\checkmark \checkmark \checkmark$ \\
\hline & Architects & & $\checkmark \checkmark \checkmark \checkmark$ & & & $\checkmark \checkmark \checkmark \checkmark$ & \\
\hline & Quantity surveyors & & $\checkmark \checkmark \checkmark \checkmark$ & & & $\checkmark \checkmark \checkmark \checkmark$ & \\
\hline & Engineers & & $\checkmark \checkmark \checkmark \checkmark$ & & & $\checkmark \checkmark \checkmark \checkmark$ & \\
\hline & Site foreman/site managers & & $\checkmark$ & $\checkmark \checkmark \checkmark$ & & $\checkmark \checkmark$ & $\checkmark \checkmark \checkmark$ \\
\hline & Workers & $\begin{array}{l}\checkmark \checkmark \checkmark \checkmark \checkmark \\
\checkmark\end{array}$ & $\begin{array}{l}\checkmark \checkmark \checkmark \checkmark \checkmark \\
\checkmark \checkmark \checkmark \checkmark\end{array}$ & & $\begin{array}{l}\checkmark \checkmark \checkmark \checkmark \checkmark \\
\checkmark \checkmark \checkmark\end{array}$ & $\checkmark \checkmark \checkmark \checkmark$ & \\
\hline \multirow{7}{*}{$\begin{array}{l}\text { Site safety inspection/ } \\
\text { monitoring/safety audit }\end{array}$} & Clients & & $\checkmark \checkmark$ & $\checkmark \checkmark$ & & $\checkmark \checkmark \checkmark$ & $\checkmark$ \\
\hline & Project managers & & $\checkmark \checkmark$ & $\checkmark \checkmark$ & & $\checkmark \checkmark$ & $\checkmark \checkmark$ \\
\hline & Architects & & $\checkmark \checkmark$ & $\checkmark \checkmark$ & & $\checkmark \checkmark \checkmark$ & \\
\hline & Quantity surveyors & & $\checkmark \checkmark \checkmark \checkmark$ & & & $\checkmark \checkmark \checkmark \checkmark$ & \\
\hline & Engineers & & $\checkmark \checkmark \checkmark \checkmark$ & & & $\checkmark \checkmark \checkmark \checkmark$ & \\
\hline & Site foreman/site manager & & $\checkmark \checkmark \checkmark \checkmark$ & & & $\checkmark \checkmark \checkmark \checkmark$ & \\
\hline & Workers & $\checkmark \checkmark \checkmark \checkmark$ & $\begin{array}{l}\checkmark \checkmark \checkmark \checkmark \checkmark \\
\checkmark \checkmark \checkmark\end{array}$ & $\checkmark \checkmark \checkmark \checkmark$ & $\checkmark \checkmark \checkmark \checkmark$ & $\begin{array}{l}\checkmark \checkmark \checkmark \checkmark \checkmark \\
\checkmark \checkmark \checkmark\end{array}$ & $\checkmark \checkmark \checkmark$ \\
\hline
\end{tabular}

time-consuming, lack of regulation which allocates roles and responsibilities for health and safety among stakeholders, and lack of knowledge. This underscores the fact that someone may have power but fails to use it due to a wrong perception, weak legal requirements or lack of knowledge.

During procurement stage as shown in Table 3 , it is noted that project managers and quantity surveyors perceive themselves to have high powers throughout project procurement stage. Further discussion revealed that they were actively involved in the tender document preparation as well as in the tender evaluation. Although these stakeholders perceive to have high power, in some cases, evaluation of health and safety aspect were lacking. The reason reported was that the evaluation process was governed by procurement regulations which do not have criteria for testing the commitment of contractors on health and safety. During the awarding of the contract, the clients' powers were high as they had to make final 
decisions on selection. Therefore, at this stage, the clients had an opportunity and authority to emphasize and ensure health and safety risks were adequately accommodated in the contracts. Further, it was revealed that conditions of contracts used are standard with general statements on health and safety aspects that do not underpin the specific issues regarding health and safety risk management.

During construction stage, Table 4 indicates that clients, project managers, architects, site managers, safety officers and site foreman had moderate power during the induction training and welfare facilities in the project construction phase. Further discussion revealed that they influenced worker training as well as induction on health and safety risk by requesting monthly training/induction reports from contractors. Furthermore, project managers were empowered by conditions of contracts that give them a mandate to issue instructions and inspect the contractor's work.

On the other hand, workers had moderate power during the construction stage. Through interviews, it was revealed that workers had power to elect safety representatives in safety committee meetings. In these meetings, workers were able to raise health and safety concerns with respect to the working environment and resolutions from these safety committee meetings were presented during monthly site meetings. This observation suggests that safety committee meetings empower and enhance workers engagement, on health and safety.

\section{Discussion}

Evidences from this study establish that majority of stakeholders perceive themselves to have high or moderate power and are able to participate in health and safety risk management because of different sources of powers they hold. For example, clients had high legitimate power and resource power. A perceived high legitimate power of clients indicates a propensity to an increased salience of duties and enhances a sense of responsibility and obligation of the project managers, designers and contractors to adhere and implement health and safety risk management. This, however, was not reflected in the three out of four projects due to lack of explicit regulations which require clients to implement health and safety risk management, low knowledge of health and safety issues, procurement procedures with limited evaluation criteria for health and safety commitment.

Project managers had both legitimate power and expert power. Through supervision, the project managers were empowered by conditions of contracts to issue instructions, inspect the contractor's work and advise clients in terms related to payment claims. High legitimate power of project managers implicates an increased health and safety commitment by the designers and contactors. On the other hand, PMs do exercise their expert power during project supervision as supervision works require necessary skills in project management $[24,25]$. It can be argued that highly perceived supervisor expert power suggests enhanced guidance and assistance for accomplishing tasks, which will therefore increase commitment of designers and contractors and positively contribute to health and safety performance.

Consultant team members such as architects, quantity surveyors and engineers have expert power. For example, designers implement a safety aspect in their design as this is their area of expertise. Likewise, quantity surveyors include safety items in the bill of quantities and cost estimates. This underscores the fact that there is high expertise power in performing specialized task in construction projects and that the implementation of health and safety risk management is an area of expertise that require such power.

On the other hand, workers are noted to possess political power. Workers exercise their political power when they elect their representatives on safety committee meetings. Political power derived from the exercise of strategic processes [10]. As a matter of fact, power seems to be a potential tool for making 
decision [4]. It is in this thinking where workers may use this power to nominate the right person who will stand for them on the issue of health and safety risk management. What is important is for the representatives to have the ability to listen and collect concerns from co-workers, and table them during the meetings and then return feedback to the co-workers.

Generally, power remains a predominant attribute in stakeholders' participation in risk management, and subsequently, has a potential to influence health and safety performance. This observation converges with the theoretical framework that power is central to participation [4]. The implication is that, effective stakeholders' participation in health and safety risk management requires the analysis of different sources of stakeholders' powers and its implementation in the project. Influences of power on stakeholders' relationship and subsequent effects underscores the potential of power as a tool for promoting effective stakeholders' participation and engendering higher levels of risk management performance. This performance benefit induces stakeholders to take a second look at their power within the project and encourage a more conscious and considerate use of power. Challenges such as wrong perception, weak regulations, and low knowledge can be addressed when we start using power as a tool for stakeholders' participation on health and safety risk management.

\section{Conclusions}

This study demonstrates that power is a predominant factor in stakeholders' participation in risk management, and it is found to have the potential to influence health and safety performance. In fact, stakeholders have different sources of power such as technical expertise, legitimate position, political position, and resource and information control. While clients and projects managers acknowledged having high power throughout project stages, other stakeholders such as architects, engineers and quantity surveyors had high power when they executed their duties. However, despite the fact that some stakeholders acknowledged having high powers in some aspects, the uses of power were generally low. This was due to low level of knowledge on health and safety risk management among stakeholders, wrong perception and weak health and safety regulations; there is also lack of stipulated roles and responsibilities for different stakeholders in matters related to health and safety and absence of employment criteria to test health and safety commitments of contractors and consultants.

To achieve an ideal form of use of stakeholders' power so as to influence health and safety risk management, there is a need to review health and safety regulations to ensure strategic responsibilities are assigned to stakeholders involved in construction projects, that workers are sensitized on health and safety issues before they start working (modality of handling toolbox and safety committee meetings. Further, it is crucial to include criteria to assess knowledge, experience and commitment of contractors to improve occupational health and safety. Lastly, there is also a need for training institutions to include health and safety modules for professionals who are involved in construction projects (architects, engineers and quantity surveyors.

\section{References}

[1] Jasperson, J. S., Carte, T. A., Saunders, C. S., Butler, B. S., Croes, H. J. P., and Zheng, W. 2002. "Review: Power and Information Technology Research: A Meta triangulation Review." MIS Quarterly 26 (4): 397-459.

[2] Etzioni, A. 1978. "Comparative Analysis of Complex Organizations." In Organizational Behavior and the Practice of Management, edited by Hampton, D., Summer, C., and Weber, R. Glenview, IL.: Scott Foresman \& Co.

[3] Folger, J., Poole, M., and Stutman, R. 1993. Working through Conflict. New York: Harper Collins.

[4] Arnstein, S. 1969. "A Ladder of Citizen Participation." American Institute of Planners 35 (4): 216-24.

[5] Freeman, E. 1984. Strategic Management: A Stakeholder Approach. Boston, MA: Pitman Publishing.

[6] Lingard, H., and Rowlinson, S. M. 2005. Occupational Health and Safety in Construction Project Management. 
London: Taylor \& Francis.

[7] French, J. R. P., and Raven, B. 1959. "The Bases of Social Power." In Studies in Social Power, edited by Cartwright, D. Michigan: Institute for Social Research, University of Michigan.

[8] Carson, P. P., Carson, K. D., and Roe, C. W. 1993. "Social Power Bases: A Meta-analytic Examination on Interrelationships and Outcomes." Applied Social Psychology 23 (14): 1150-69.

[9] Finkelstein, S. 1992. "Power in Top Management Teams: Dimensions, Measurement, and Validation." Academy of Management 35: 505-38.

[10] Lunenburg, F. 2012. "Power and Leadership: An Influence Process." Management, Business, and Administration 15 (1) : 1-9.

[11] McShane, S. L., and Von Glinow, M. A. 2011. Organizational Behavior. 5th ed. New York, NY: McGraw-Hill Irwin.

[12] Kudisch, J. D., Poteet, M. L., Dobbins, G. H., Rush, M. C., and Russell, J. E. A. 1995. "Expert Power, Referent Power, and Charisma: Toward the Resolution of a Theoretical Debate." Business and Psychology 10: 177-95.

[13] Luthans, F. 2011. Organizational Behavior. 11th ed. New York, NY: McGraw-Hill Irwin.

[14] Liu, A., Fellow, R., and Fang, Z. 2003. "The Power Paradigm of Project Leadership." Construction Management and Economics 2 (8): 819-29.

[15] Hersey, P., Blanchard, K. H., and Johnson, D. E. 1996. Management of Organizational Behavior: Utilize Human Resource. 7th ed. Upper Sandle River : Prentice Hall.

[16] Chapman, C., and Ward, S. 2003. Project Risk Management: Processes, Techniques and Insights. 2nd ed. Chichester: Wiley.

[17] Kikwasi, G. J. 2009. "Client Involvement in Health and Safety of Construction Project at Various Phases of the Project." Building and Land Development 16 (1\&2): 30-43.

[18] Lingard, H., Blismas, N., Cook, T., and Cooper, A. 2009. "The Model Client Framework, Resources to Help Austrian Government Agencies to Promote Safe Construction." Managing Project in Business 2 (1):
$131-40$.

[19] Musonda, I. 2012. "Construction Health and Safety (H\&S) Performance Improvement. A Client-Centred Model." $\mathrm{PhD}$ thesis, University of Johannesburg.

[20] HSE (Health and Safety Executive). 2007. Managing Health and Safety in Construction: Construction (Design and Management) Regulations 2007 Approved Code of Practice. London: HSE.

[21] CIDB (Construction Industry Development Board). 2008. Construction Health and Safety in South Africa-Status and Recommendations. Pretoria: CIDB.

[22] Swedish Government. 2009. The Working Environment $\operatorname{Act}(A M L)$. The Swedish Work Environment Authority.

[23] Huang, X., and Hinze, J. 2006. "Owner's Role in Construction Safety." Construction Engineering and Management 132: 164-73.

[24] Rwelamila, P. M. D., and Asalan, R. 2010. "Understanding of Project Management Good Practices by Construction Project Managers: The Case of ABCD." In Proceeding 26th Annual ARCOM Conference, 1189-98.

[25] Weaver, P. 2007. "A Simple View of Complexity in Project Management." In Proceeding of 4th World Project Management Week Singapore, 1-13.

[26] Smallwood, J. J. 2004. "The Influence of Engineering Designers on Health and Safety During Construction." The South African Institution of Civil Engineers 46 (1): 2-8.

[27] Niemandt, P. S., and Crafford, G. J. 2011. "The Influence of Quantity Surveyors on the Construction Industry's Occupational Health and Safety." In Proceeding 6th Built Environment Conference, 168-80.

[28] The United Republic of Tanzania. 2003. Occupational Health and Safety Act 2003. Dar es Salaam Government printer.

[29] The United Republic of Tanzania. 2010. The Contractors Registration Board, Act No. 4 of 2010. Dar es Salaam Govenment printer.

[30] The United Republic of Tanzania. 2004. Employment and Labour Relation Act 2004. Dar es Salaam Government printer. 